\title{
The SARS-CoV-2 Crisis: Has Medicine Finally Entered a Reductionist Era?
}

\author{
Rainer Johannes Klement \\ Department of Radiation Oncology, Leopoldina Hospital, Schweinfurt, Germany
}

\begin{abstract}
" $[\mathrm{M}]$ odern medicine is not an aggregate but a system of disciplines, and its practitioners interact with one another because each of them knows a part of the same whole" [1]. If this description of modern medicine by the physicist and philosopher Mario Bunge from 2013 is correct, then the SARS-CoV-2 crisis reveals that medicine has finally entered a postmodern, reductionist era. Instead of the interdisciplinary and transdisciplinary approach envisioned in the above quote, which requires a systems thinking perspective from individual members of the different disciplines working together, the SARS$\mathrm{CoV}-2$ crisis is in many ways a crisis of reductionism [2].
\end{abstract} It has been stressed that public health problems such as climate change [3] and infectious disease outbreaks [4] would greatly benefit from an interdisciplinary, or better transdisciplinary, approach. While the former involves scientists working jointly together to tackle a specific problem, but still from their individual discipline-specific perspective, the latter approach transcends disciplinary boundaries as researchers draw together discipline-specific concepts and theories to develop a new understanding of a complex problem [5]. Transdisciplinarity requires systems thinking. Systems thinking is a set of skills to recognize parts of systems and their interconnection, identify and understand cause-effect feedback loops, and understand system structure, dynamic behavior, and systems at different scales - in other words, systems thinking is the ability of seeing both the forest and the trees [6].

How should systems thinking and transdisciplinarity have been applied to the SARS-CoV-2 crisis? A first step should have been the attempt to massively and rapidly collect data from many different sources [4]. This would have constituted the basis for identifying the dynamics of the outbreak on regional and global scales as well as susceptibility and disease course on the level of the individ- ual. In retrospect, the scientific community and responsible institutions must confess that they have failed in this attempt, because such data collection would have required the following actions: (i) Efforts to reliably estimate the SARS-CoV-2 tests' sensitivity and specificity as well as reliably assessing the number of infected people in the target population (prevalence) by testing representative random samples of this population. This would have provided a reliable denominator (prevalence of the infected) to which the COVID-19 deaths (numerator) could be related. The prevalence and test performance measures are crucial to interpret a positive SARS-CoV-2 test result $[7,8]$. However, there is still no "gold standard" which the widely used RT-PCR tests could be compared to in order to reliably estimate test performance. Instead of acknowledging these limitations, positive test results are routinely counted as definite evidence that the tested individual is infected with SARS-CoV-2. (ii) Conduction of autopsies on deceased patients with suspected COVID-19. This would have been required to differentiate between patients dying with or because of SARS-CoV-2. To date, however, autopsies have been performed sparsely, and patients dying with a positive test result are generally counted as COVID-19 deaths. (iii) International cooperation in data collection. This would have required the understanding that we live in an interconnected world where lives depend on each other. However, data were collected within countries and their subregions, interpreted within frameworks of national security, and used to justify the proclamation of national states of emergency and nationwide lockdowns [9].

In a second and third step of applying systems thinking to the SARS-CoV-2 crisis, the analysis of the data collected from various sources would depend on their rapid dissemination and transdisciplinary science [4]. Exam- 
ples for transdisciplinary science include research into the modulation of COVID-19 risk and disease severity through nutrients such as vitamin D [10] ("nutritional immunology") or research into the effects of media-driven "angst campaigns" and quarantining measures on mental health and the immune system ("psychoneuroendocrinology") [11-13]. It also involves balancing benefits and harms in patient treatment and public health policies by recognizing and weighting insights from different medical systems, i.e., evolutionary, evidence-based, personalized, value-driven, and complementary medicine [14]. However, none of these transdisciplinary considerations have been openly discussed; instead, discussions were dominated by the reductionist view on a "killer virus" driving hospital alerting and political actions, and often led by a few virologists standing in the spotlight of media attention, similar to past pandemics [15].

Lastly, Leischow et al. [4] mention modeling of the complex relationships among the components of the system under consideration from within a transdisciplinary perspective as important tools to inform policymakers. This involves the construction of causal feedback loops, such as a recently published preliminary diagram showing the complexity of the SARS-CoV-2 problem [16], as well as computer models fed by the collected data. Given the inadequate data collection strategy, the poor quality of the data, and lack of transdisciplinary science thus far, it must be assumed that the models that were used to justify the lockdowns in many countries were not realistic.
For example, these models usually neglect the fact that some people never contract an infection due to innate immunity - if this fact is taken into account, the herd immunity threshold may be reached once that $10-20 \%$ of a population are immune [17]. Also, the assumed infection fatality rates in some of the published computer simulations are much too high (e.g., 0.9 in Ferguson et al. [18] or $0.91-1.26 \%$ in Flaxman et al. [19]), since more recent data indicate values of $0.02-0.78 \%$ (median $0.25 \%$ ) [20].

We see that the potential of systems thinking and transdisciplinary science has not yet been utilized in the attempt to overcome the SARS-CoV-2 crisis [2]. We could potentially benefit if more appropriately trained, industry- and financially independent scientists who see both the forest and the trees started working together.

\section{Acknowledgement}

I deeply thank Prof. Dr. Ulrich Keil for his thoughts and comments on this editorial.

\section{Conflict of Interest Statement}

The author declares that he has no competing interests.

\section{Funding Sources}

No funding has been received for the writing of this paper.

\section{References}

1 Bunge M. Medical Philosophy: Conceptual Issues in Medicine. 1st ed. Singapore: World Scientific Publishing Co Pte Ltd; 2013.

2 Klement RJ. The SARS-CoV-2 crisis: A crisis of reductionism? Public Health. 2020 Jun;185: $70-1$.

3 Bhaskar R, Frank C, Høyer KG, Næss P, Parker J, editors. Interdisciplinarity and Climate Change: Transforming Knowledge and Practice for Our Global Future. 1st ed. New York: Routledge; 2010.

4 Leischow SJ, Best A, Trochim WM, Clark PI, Gallagher RS, Marcus SE, et al. Systems thinking to improve the public's health. Am J Prev Med. 2008 Aug;35(2 Suppl):S196-203.

5 Rosenfield PL. The potential of transdisciplinary research for sustaining and extending linkages between the health and social sciences. Soc Sci Med. 1992 Dec;35(11):1343-57.

6 Arnold RD, Wade JP. A definition of systems thinking: a systems approach. Procedia Comput Sci. 2015;44:669-78.

7 Klement RJ, Bandyopadhyay PS. The epistemology of the SARS-CoV-2 test. Available online at: https://doi.org/10.21203/rs.3.rs-23658/ v1.

8 Watson J, Whiting PF, Brush JE. Interpreting a covid-19 test result. BMJ. 2020 May;369: $\mathrm{m} 1808$.
9 Everts J. The dashboard pandemic. Dialogues Hum Geogr. 2020;10(2):260-4.

10 D’Avolio A, Avataneo V, Manca A, Cusato J, De Nicolò A, Lucchini R, et al. 25-hydroxyvitamin $\mathrm{D}$ concentrations are lower in patients with positive PCR for SARS-CoV-2. Nutrients. 2020 May;12(5):1-7.

11 Guo Q, Zheng Y, Shi J, Wang J, Li G, Li C, et al. Immediate psychological distress in quarantined patients with COVID-19 and its association with peripheral inflammation: a mixed-method study. Brain Behav Immun. 2020 May;88:17-27.

12 Holmes EA, O'Connor RC, Perry VH, Tracey I, Wessely S, Arseneault L, et al. Multidisciplinary research priorities for the COVID-19 pandemic: a call for action for mental health science. Lancet Psychiatry. 2020 Jun;7(6):547-60.

13 Razai MS, Oakeshott P, Kankam H, Galea S, Stokes-Lampard H. Mitigating the psychological effects of social isolation during the covid-19 pandemic. BMJ. 2020 May;369:m1904.

14 Thompson RP, Upshur REG. The varieties of modern medicine. In: Philosophy of Medicine: An Introduction. New York: Routledge; 2018. p. 170-181.

15 Keil U, Schönhöfer P, Spelsberg A. The invention of the swine-flu pandemic. Eur J Epidemiol. 2011 Mar;26(3):187-90.
16 Sahin O, Salim H, Suprun E, Richards R, MacAskill S, Heilgeist S, et al. Developing a preliminary causal loop diagram for understanding the wicked complexity of the COVID-19 pandemic. Systems. 2020;8(2):20.

17 Gomes MGM, Corder RM, King JG, Langwig KE, Souto-Maior C, Carneiro J, et al. Individual variation in susceptibility or exposure to SARS-CoV-2 lowers the herd immunity threshold. medRxiv 2020 doi: 10.1101/2020. 04.27.20081893 [preprint].

18 Ferguson NM, Laydon D, Nedjati-Gilani G, Imai N, Ainslie K, Baguelin M, et al. Report 9: Impact of non-pharmaceutical interventions (NPIs) to reduce COVID-19 mortality and healthcare demand. Available online at: https://doi.org/10.25561/77482.

19 Flaxman S, Mishra S, Gandy A, Unwin HJ, Mellan TA, Coupland H, et al.; Imperial College COVID-19 Response Team. Estimating the effects of non-pharmaceutical interventions on COVID-19 in Europe. Nature. 2020 doi: 10.1038/s41586-020-2405-7 [Epub ahead of print].

20 Ioannidis J. The infection fatality rate of COVID-19 inferred from seroprevalence data. medRxiv2020 doi:10.1101/2020.05.13.20101253 [preprint]. 